\title{
Activation of cell-penetrating peptide fragments by disulfide formation
}

\author{
Raheleh Tooyserkani ${ }^{1} \cdot$ Wojciech Lipiński ${ }^{1}$ Bob Willemsen ${ }^{1}$ • Dennis W. P. M. Löwik ${ }^{1}$ (1)
}

Received: 21 April 2020 / Accepted: 26 July 2020 / Published online: 31 July 2020

(c) The Author(s) 2020

\begin{abstract}
Three cell-penetrating peptides (CPPs), Tat, Pep-3 and penetratin, were split into two parts and each fragment was terminated with a cysteine residue, to allow disulfide bridge formation, as well as a fluorescent label, for visualization and quantitative analysis. After disulfide formation between two complementary CPP fragments, cellular uptake of the resulting conjugates was observed. As confirmed by in vitro experiments, the conjugated peptides showed uptake activity comparable to the native CPP sequences, while the truncated peptides were hardly active. Until now, this split CPP strategy has only been demonstrated for oligo-arginine CPPs, but here we demonstrate that it is also applicable to other cell-penetrating peptides. This wider applicability may help in the design of new activatable cell-penetrating peptides for, e.g., targeted drug delivery.
\end{abstract}

Keywords Cell-penetrating peptide $\cdot$ Cellular uptake $\cdot$ Disulfide conjugation $\cdot$ Tat $\cdot$ Pep- $3 \cdot$ Penetratin

\section{Introduction}

In the search for new, efficient delivery methods of therapeutic molecules and particles into cells, cell-penetrating peptides (CPPs) emerged 30 years ago as extraordinary vector molecules (Copolovici et al. 2014). They can facilitate transmembrane transport through a receptor-independent pathway and without inducing toxicity. However, despite a great number of both natural and synthetic CPPs that have been discovered, varying in their chemical structure and exhibiting different properties, the common use of CPPs as delivery vectors is hampered due to a number of practical difficulties (Feni and Neundorf 2017; Shi et al. 2014). Firstly, because the mechanism of cellular uptake remains elusive in many cases, and as it seems to be significantly dependent on the type of cargo, type of cells and experimental conditions, it is

Handling editor: F. Albericio.

Electronic supplementary material The online version of this article (https://doi.org/10.1007/s00726-020-02880-x) contains supplementary material, which is available to authorized users.

Dennis W. P. M. Löwik

dennis.lowik@ru.nl

1 Radboud University Nijmegen, Institute for Molecules and Materials, Bio-Organic Chemistry, Heyendaalseweg 135, 6525 AJ Nijmegen, The Netherlands very difficult to develop an all-embracing delivery solution based on CPPs (Madani et al. 2011). Secondly, and probably even more important, CPPs are taken up non-selectively in a great variety of cells. Hence, several strategies have been developed to improve the selectivity of CPP-based delivery platforms. For example, CPPs or CPP-based delivery platforms can be coupled to targeting ligands (e.g., hyaluronic acid, (Yamada et al. 2015) folic acid (Li et al. 2016), transferrin (Sharma et al. 2016), bombesin (Nallely et al. 2013), RGD or NGR sequence (Xie et al. 2016)) or can be incorporated into macromolecular carriers (e.g., nanoparticles (Morshed et al. 2016), polymers (Chen et al. 2012) or liposomes (Yang et al. 2014)). In addition, a very promising strategy is the reversible inactivation of CPPs and creating so-called activatable cell-penetrating peptides (aCPPs), of which membrane-penetrating abilities can be elicited by an external trigger [e.g., enzymatic cleavage (Bode et al. 2015; Jiang et al. 2004), pH change (Jin et al. 2013) or irradiation (Hansen et al. 2012; Wang et al. 2018)] at the site of action. In our own laboratory, we have developed a strategy that deploys the conjugation of inactive fragments (Fig. 1a). We showed that four-mer and five-mer fragments of the wellknown CPPs octa- and nona-arginine show very little uptake in comparison to the full length peptide, but that these truncated peptides regained their cellular uptake ability upon reconstitution to a molecule containing at least eight arginine residues. This reconstitution was achieved both covalently, 
Fig. 1 General concept of the activation of split CPPs (a) and the Tat, Pep-3 and Pen-based peptide sequences used in this study (b)
A

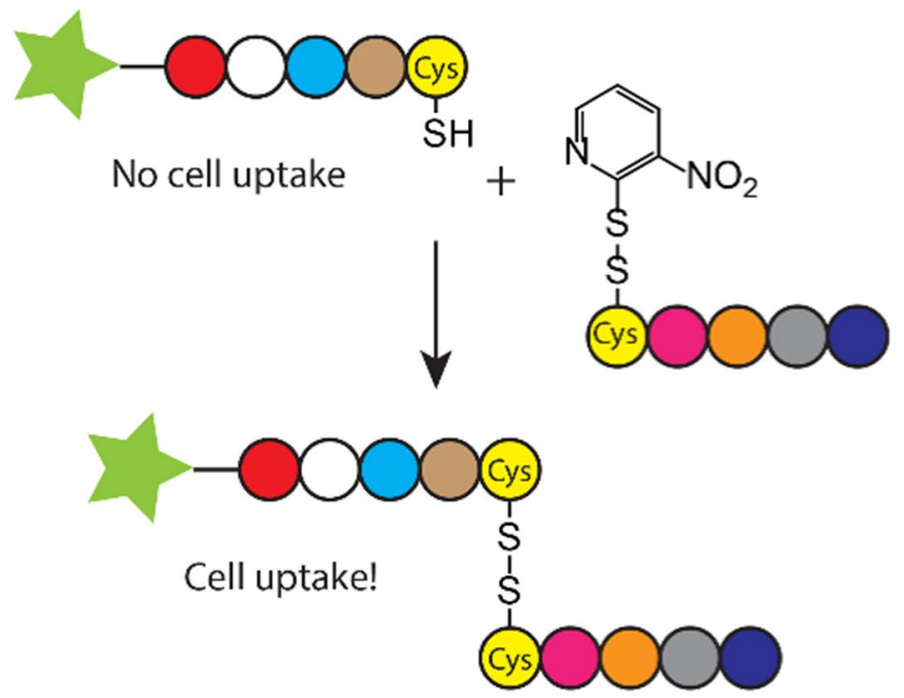

B

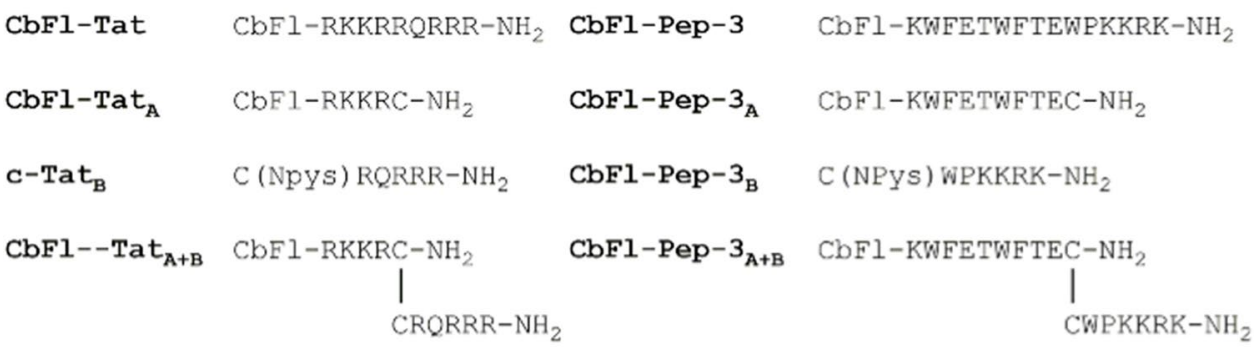

$\begin{array}{lc}\text { CbFl-Pen } & \text { CbFl-RQTKIWFQNRRMKWKK-NH } \\ \text { CbFl-Pen } & \text { CbFl-RQIKIWFQNRC-NH } \\ \text { C-Pen } & \text { C(NPYS) RMKWKK-NH } \\ \text { CbFl-Pen } & \text { CbFl-RQIKIWFQNRC-NH } \\ & \\ & \\ & \end{array}$

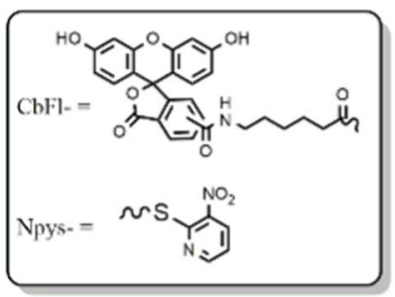

by disulfide bond formation (Bode et al. 2014) and inverse electron demand Diels-Alder bio-conjugations (Bode et al. 2019), as well as non-covalently through the interaction of a leucine zipper pair. (Bode et al. 2017).

To date, this split CPP strategy has only been demonstrated for oligo-arginines and these are not always the best option when choosing a CPP. Therefore, we wanted to investigate whether our strategy to construct activatable split CPPs is also applicable to fundamentally different CPPs than oligo-arginines. To this purpose, we selected three CPPs from different classes: Tat, a cationic CPP still closely related to octa- and nona-arginine, but also Pep-3 and penetratin (Pen), both amphipathic CPPs and quite distinct from Tat and the related oligo-arginines. We chose disulfide formation as the method of conjugation for the fragments because of its synthetic simplicity. Tat peptide is a very well-studied, cationic CPP derived from the HIV TAT protein (Brooks et al. 2005). Pep-3 is a rationally designed primary amphipathic CPP comprising a tryptophan/phenylalanine-rich hydrophobic domain and a lysine/arginine-rich hydrophilic motif (Morris et al. 2007). Penetratin is derived from the third $\alpha$-helix of the homeodomain of Antennapedia, a Drosophila homeoprotein (Derossi et al. 1994).

\section{Results and discussion}

As mentioned above, the aim of this study was to investigate the compatibility of our split CPP inactivation-activation strategy with three different CPPs (Fig. 1b). To this end, we synthesized Tat (RKKRRQRRR), Pep-3 (KWFETWFTEWPKKRK) and penetratin, 
(RQILIWFQNRRMKWKK). Moreover, we labeled all three $\mathrm{N}$-terminally with $5(6)$-carboxyfluorescein $(\mathrm{Cbfl})$ in combination with an $\varepsilon$-aminohexanoic acid (6Ahx) spacer to yield CbFl-Tat, CbFl-Pep-3 and CbFl-Pen, respectively, that serve as reference CPPs. We chose to divide the Tat sequence into two moieties such that each fragment contained four basic amino acids following our earlier strategy that we used for octa-arginine (Bode et al. 2014). The Pep-3 sequence we split to yield a hydrophobic and a hydrophilic fragment, comprising, respectively, nine and six amino acids of the full length sequence. We decided to fragment Pen in a 10-mer N-terminal and a 6-mer C-terminal fragment, which were shown by Fisher et al., in a structure activity relationship study, to give minimal uptake compared to the full length Pen (Fischer et al. 2000). The N-terminal fragments, also all labeled with $\mathrm{Cbfl}$ and connected via a 6Ahx spacer, had a cysteine residue added to their $\mathrm{C}$-terminus to give $\mathrm{CbFl}-\mathrm{Tat}_{\mathrm{A}}$, $\mathrm{CbFl}$ Pep- $3_{\mathrm{A}}$ and CbFl-Pen ${ }_{\mathrm{A}}$. The C-terminal parts, $\mathrm{c}-\mathrm{Tat}_{\mathrm{B}}$, c-Pep- $3_{\mathrm{B}}$ and c-Pen ${ }_{\mathrm{B}}$, had a cysteine residue added to their $\mathrm{N}$-terminus with a 3-nitro-2-pyridinesulfenyl (Npys) group on the thiol group that allowed for a facile preparation of the corresponding reconstituted peptides, CbFl-Tat ${ }_{\mathrm{A}+\mathrm{B}}$, CbFl-Pep- $3_{\mathrm{A}+\mathrm{B}}$ and CbFl-Pen $\mathrm{A}_{\mathrm{A}}$. Mixing both parts of the split CPPs at $\mathrm{pH} 7.4$ resulted in a smooth formation of the disulfide-linked peptides comprising all amino acids of the native sequences. (We prepared $\mathrm{Pen}_{\mathrm{A}+\mathrm{B}}$ in $\mathrm{DMF}$ because the $\mathrm{Pen}_{\mathrm{A}}$ fragment would not dissolve in aqueous media.) All synthesized peptides were purified by preparative HPLC, and all products were obtained with a purity greater than or equal to $95 \%$, as assessed by analytical reversed phase HPLC. All sequences are summarized in Fig. $1 b$.

With these peptides in hand, we first determined the uptake efficiency of the Cbfl labeled peptides at a concentration of $5 \mu \mathrm{M}$ by incubating them with HeLa cells in serum containing medium for $30 \mathrm{~min}$ at $37^{\circ} \mathrm{C}$. Like in our earlier study, we quantified uptake using flow cytometry and visualized it by confocal fluorescence microscopy (Bode et al. 2014). Both flow cytometry and confocal microscopy revealed that the reconstituted peptide $\mathrm{CbFl-Tat}{ }_{\mathrm{A}+\mathrm{B}}$ was internalized with an efficiency that is comparable to the native peptide, CbFl-Tat, as is shown in Fig. 2. Moreover, the truncated peptide $\mathrm{CbFl}_{-} \mathrm{Tat}_{\mathrm{A}}$ expressed relatively low activity in comparison to $\mathrm{CbFl}-\mathrm{Tat}$ and $\mathrm{CbFl}-\mathrm{Tat}_{\mathrm{A}+\mathrm{B}}$, comparable to what we found for truncated oligo-arginine in our earlier study (Bode et al. 2014).

Hence, we can conclude that our activation strategy based on the ligation of fragments can be successfully applied for the Tat peptide. However, it must be noted that the Tat peptide is very closely related to oligo-arginine, which we studied before and in which the presence of charge is a dominant factor that influences CPP behavior. Therefore, we continued with the more distinct Pep-3 and penetratin, from the class of so-called primary and secondary amphipathic CPPs (Madani et al. 2011; Zaro and Shen 2015).

As for the Tat-derived peptides, the uptake efficiency of the Pep-3 derived peptides was quantified at a concentration of $5 \mu \mathrm{M}$ in HeLa cells using flow cytometry and visualized by confocal fluorescence microscopy (Fig. 2). Flow cytometry results suggest that the $\mathrm{N}$-terminal fragment CbFl-Pep${ }_{3 \mathrm{~A}}$ is only slightly less (58\%) efficiently taken up by the HeLa cells than the full length sequence CbFl-Pep- 3 and the reconstituted peptide CbFl-Pep- $3_{\mathrm{A}+\mathrm{B}}$. Possibly, we could have split the CPP into two different parts to achieve a better inactivation. Nevertheless, the reconstituted $\mathrm{CbFl}-\mathrm{Pep}-3_{\mathrm{A}+\mathrm{B}}$ was taken up as efficiently as the native CbFl-Pep-3, which suggests that our strategy of activation by reconstitution is also viable for CPP distinct from the arginine-rich ones.

Next, we moved to penetratin of which it was fortunately already known, from a SAR study by Fisher et al., (Fischer et al. 2000) that the fragments we split the peptide into are barely taken up. Indeed, we corroborated that the truncated CbFl-Pen ${ }_{\mathrm{A}}$ is hardly taken up in HeLa cells at a concentration of $5 \mu \mathrm{M}$ (Fig. 2) Satisfyingly, the reconstituted CbFl$\mathrm{Pen}_{\mathrm{A}+\mathrm{B}}$ was able to enter HeLa cells almost as efficiently as the native full length $\mathrm{CbFl}-\mathrm{Pen}$.

Because it is known that the cellular uptake behavior of CPPs can be concentration dependent, we decided to test our peptides also at a concentration of $20 \mu \mathrm{M}$, as we did in our earlier study with oligo-arginines (Bode et al. 2014; Brock 2014). Again, we studied the peptides by incubating them with HeLa cells in serum containing medium for $30 \mathrm{~min}$ at $37{ }^{\circ} \mathrm{C}$ and we quantified uptake using flow cytometry and visualized it by confocal fluorescence microscopy as is shown in Fig. 3.

We found that also at $20 \mu \mathrm{M}$, reconstituted peptide $\mathrm{CbFl}^{-\mathrm{Tat}_{\mathrm{A}+\mathrm{B}}}$ was taken up with an efficiency comparable to the native peptide CbFl-Tat and that the truncated peptide $\mathrm{CbFl-Tat}{ }_{\mathrm{A}}$ was poorly taken up compared to the native $\mathrm{CbFl}-\mathrm{Tat}$ and reconstituted $\mathrm{CbFl-Tat}{ }_{\mathrm{A}+\mathrm{B}}$. The only difference with the incubation at $5 \mu \mathrm{M}$ was that the activity of both CbFl-Tat and $\mathrm{Tat}_{\mathrm{A}+\mathrm{B}}$ was much higher, which was expected at this higher concentration. For Pep-3, however, at $20 \mu \mathrm{M}$ the reconstituted peptide CbFl-Pep$3_{\mathrm{A}+\mathrm{B}}$ was taken up only half as efficiently as the native peptide, while the activity of short hydrophobic N-terminal peptide CbFl-Pep- $3_{\mathrm{A}}$ displayed $20 \%$ of the activity of CbFl-Pep-3. According to confocal microscopy analysis, these differences did not seem to be as pronounced, but nevertheless follow the same trend as the FACS results as can be seen in Fig. 3. This poor activation at $20 \mu \mathrm{M}$ cannot be ascribed to toxicity, as none of the peptides in this study proved to be highly toxic (see supporting information). Finally, for penetratin we found again that the disulfide-bridged $\mathrm{CbFl}-\mathrm{Pen}_{\mathrm{A}+\mathrm{B}}$ was taken up comparably 
Fig. 2 Summary of flow

cytometry results a for the Tat, Pep-3 and penetratin-derived peptides and the corresponding confocal fluorescence images (b). The uptake was studied by incubating the peptides at $5 \mu \mathrm{M}$ in serum-containing medium, for $30 \mathrm{~min}$ at $37^{\circ} \mathrm{C}$. Uptake of CbFl-Tat, CbFl-Pep-3 and CbFlPen were each set to $100 \%$

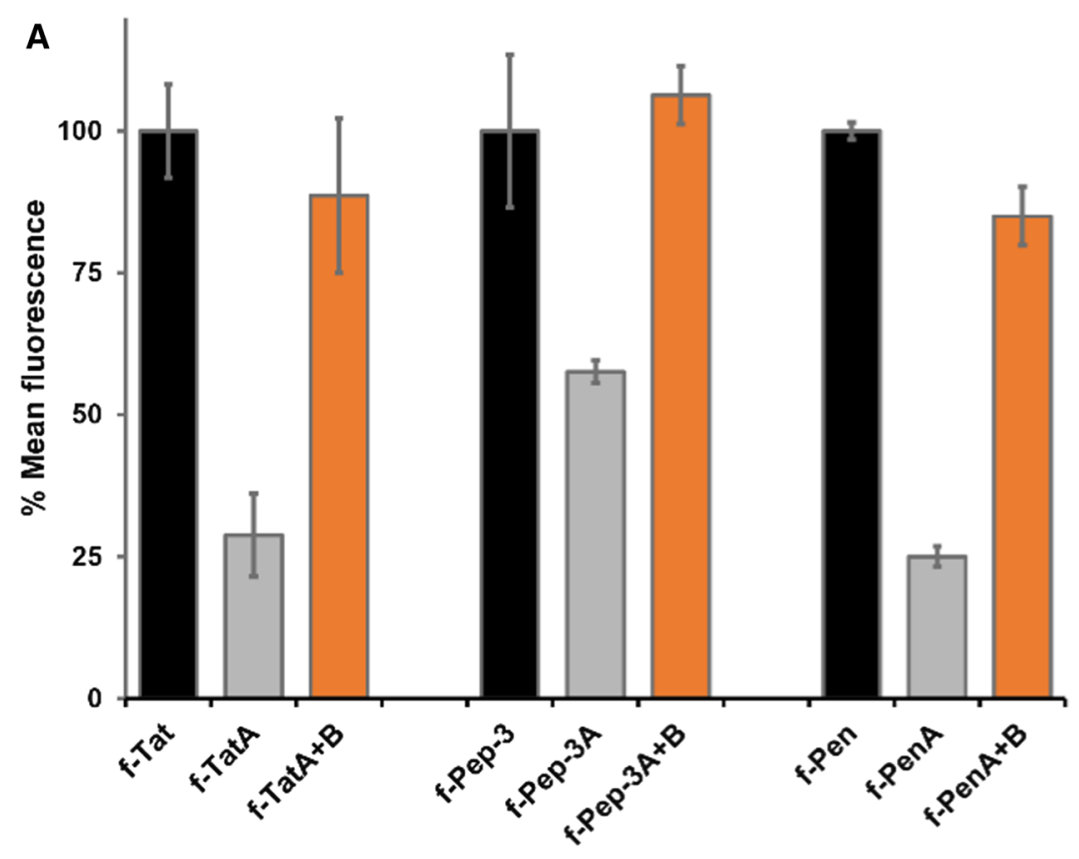

B
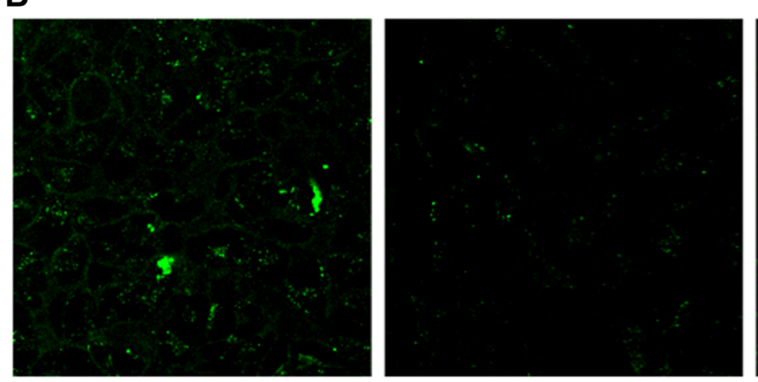

f-Tat
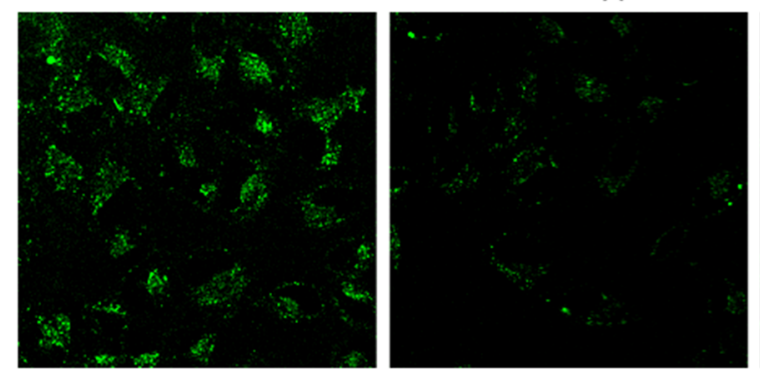

f-Pep-3

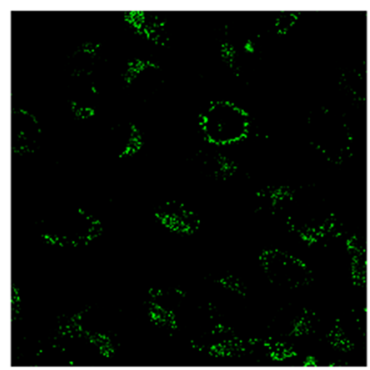

f-Pep-3

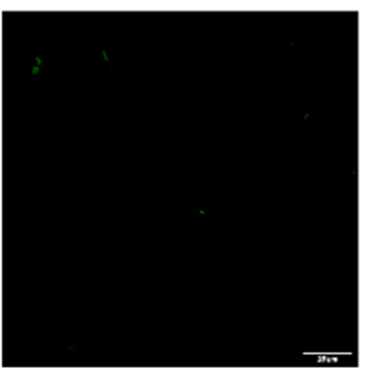

f-Pen
f-Tat $_{A}$

f-Pen $_{A}$

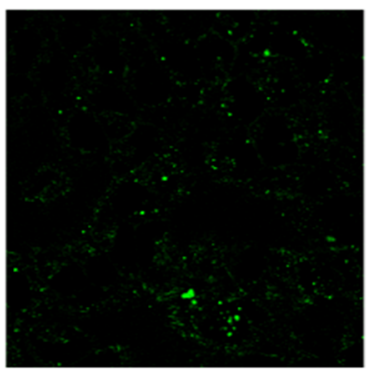

f-Tat $_{A+B}$

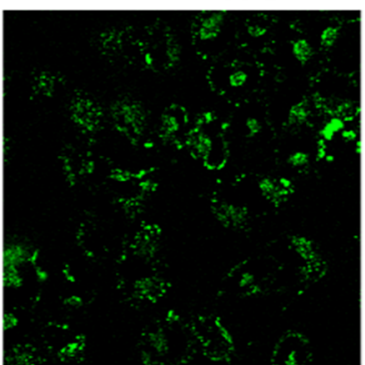

f-Pep- $3_{A+B}$

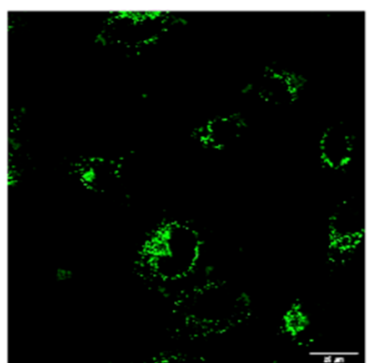

f-Pen ${ }_{A+B}$ 
Fig. 3 Summary of flow cytometry results a for the Tat, Pep-3 and penetratin-derived peptides and the corresponding confocal fluorescence images (b). The uptake was studied by incubating the peptides at $20 \mu \mathrm{M}$ in serum-containing medium, for $30 \mathrm{~min}$ at $37^{\circ} \mathrm{C}$. Uptake of CbFl-Tat, CbFl-Pep-3 and CbFlPen were each set to $100 \%$.

ND: not determined because of insolubility of the peptide

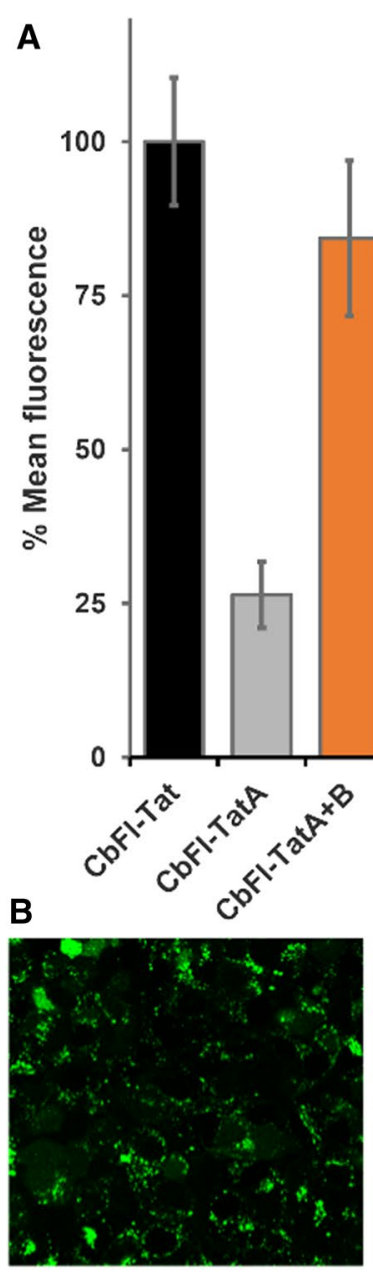

CbFI-Tat

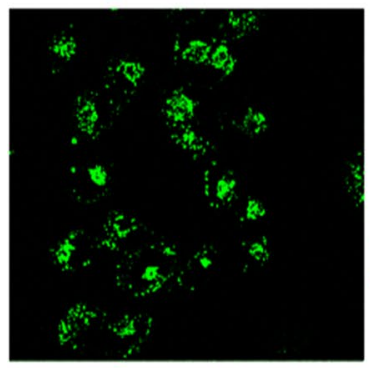

CbFI-Pep-3

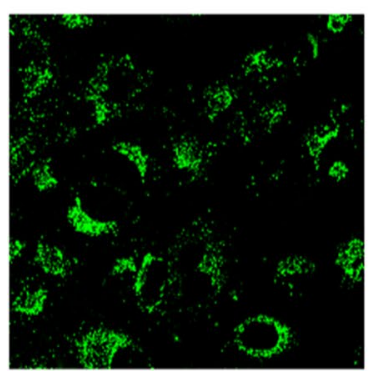

CbFI-Pen

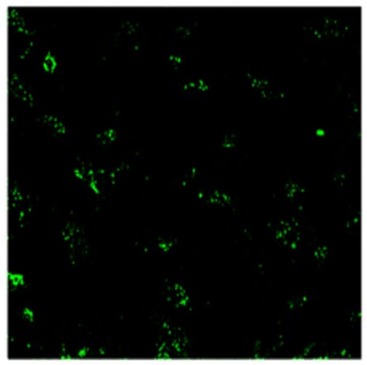

CbFI-Pep-3

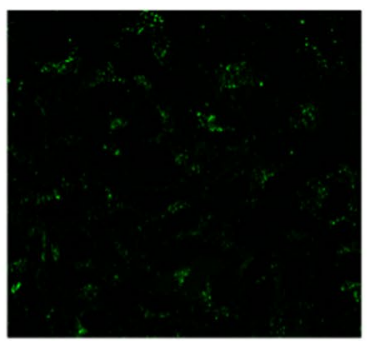

$\mathrm{CbFI}_{\mathrm{Tat}}$

CbFI-Tat $_{\mathrm{A}+\mathrm{B}}$

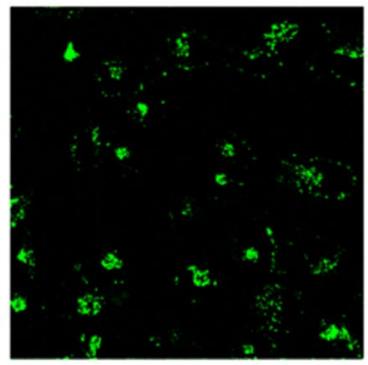

CbFI-Pep- $3_{A+B}$

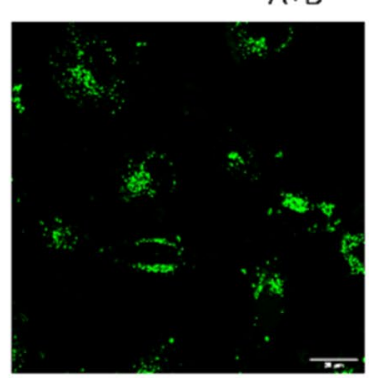

$\mathrm{CbFI}_{-\mathrm{Pen}_{\mathrm{A}+\mathrm{B}}}$ 
to the native CbFl-Pen. However, at the concentration of $20 \mu \mathrm{M}$ the $\mathrm{N}$-terminal part CbFl-PenA turned out to be insoluble in aqueous media. Also, the addition of small amounts of organic co-solvent could not keep the peptide in solution at this concentration. Therefore, we could not determine the uptake of this particular fragment. Possibly, when we would attach CbFl-Pen ${ }_{\mathrm{A}}$ to a much larger cargo, the lower solubility would be less of an issue.

\section{Conclusion}

In conclusion, we have shown that the strategy of CPP activation based on reconstitution from shorter fragments via disulfide formation is also applicable to CPPs other than oligo-arginines. We postulate that all cationic CPPs, whose activity is not strictly related to their secondary structure, may be activated by connecting truncated fragments. On the other hand, experiments with Pep-3-derived peptides did not lead to an unambiguous conclusion. At $5 \mu \mathrm{M}$, the reconstituted peptide was taken up equally well as the native peptide. Somehow, the truncated version still displayed considerable uptake properties. Similar behavior has been observed for penetratin when truncated (Fischer et al. 2000). A better inactivation might be achieved by splitting the peptide at a different position. The penetratin derivatives showed uptake behavior similar to those of oligo-arginine and Tat. Truncated $\mathrm{Pen}_{\mathrm{A}}$ is hardly taken up, while the disulfide bridged fragments are taken up as efficiently as the native full length penetratin itself. These results show that our split CPP strategy is also applicable beyond mere cationic CPPs such as oligo-arginines and Tat.

At $20 \mu \mathrm{M}$, the strategy was less as successful in the case of Pep-3. Apparently, a different uptake mechanism might apply in this case where more specific interactions with the cell membrane or the formation a secondary structure could be of more importance for the induction of cellular uptake. Perhaps, the influence of the additional cysteine residues and concomitant disulfide bridge might be too disruptive on the Pep-3 activity. We are also investigating other ligation methods for reconstitution to possibly resolve this problem (Bode et al. 2019). For both Tat and penetratin, our strategy of activation by reconstitution worked, although the uptake of the $\mathrm{N}$-terminal penetratin fragment could not be established due to its insolubility in aqueous media at $20 \mu \mathrm{M}$. Concluding, we think our strategy could find applications in targeted drug delivery based on activatable cell-penetrating peptides, especially when combined with other bio-orthogonal conjugation chemistry that we have shown to work for oligo-arginines (Bode et al. 2019).

\section{Experimental}

\section{General}

Unless stated otherwise, all chemicals were purchased from commercial sources and all reactions were carried out under ambient atmosphere. Breipohl resin was obtained from Bachem (Bubendorf, Switzerland). Fmocamino acids were purchased from Novabiochem (EMD Chemicals, Gibbstown, USA.), Fmoc-6-Ahx-OH was acquired from Iris Biotech GMBH (Marktredwitz, Germany) and carboxyfluorescein was obtained from Acros Organics (Geel, Belgium). MilliQ was doubly deionized using a Labconco Water Pro PS purification system (18.1 $\mathrm{M} \Omega$ ).

Analytical HPLC was performed on a Shimadzu LC20A system, equipped with a C18 ReproSil column $(15 \mathrm{~cm} \times 3 \mathrm{~mm}, 3 \mu \mathrm{m})$. A gradient program was used, $5-100 \%$ of phase B in phase A during $40 \mathrm{~min}$ (phase A: $100 \% \mathrm{H} 2 \mathrm{O}+0.1 \%$ TFA, phase $\mathrm{B}: 100 \% \mathrm{MeCN}+0.1 \%$ TFA), flow $0.4 \mathrm{ml} / \mathrm{min}$.

Preparative HPLC was performed on a Shimadzu LC-20A system, equipped with an NX-C18 column $(15 \mathrm{~cm} \times 21.2 \mathrm{~mm}, 10 \mu \mathrm{m})$. A gradient program was used $5-100 \%$ of phase B in phase A (phase A: $100 \%$ $\mathrm{H} 2 \mathrm{O}+0.1 \%$ TFA, phase $\mathrm{B}: 100 \% \mathrm{MeCN}+0.1 \% \mathrm{TFA})$, flow $6.0 \mathrm{ml} / \mathrm{min}$.

Mass spectra were acquired on a Thermo Finnigan LCQ Advantage Max (ESI-Q) system or on a Bruker Microflex LRF (MALDI-ToF) system (with $\alpha$-cyano-4hydroxycinnamic acid matrix).

\section{Peptide synthesis}

Peptides were synthesized on polystyrene Breipohl amide resin using a Labortec SP4000 peptide synthesizer employing a standard Fmoc solid-phase peptide synthesis (SPPS) protocol. In brief, the resin was swollen in DMF for 60 min prior to use. The Fmoc protecting groups were removed by shaking the resin with piperidine in DMF $(20 \%, \mathrm{v} / \mathrm{v})$ for three times $6 \mathrm{~min}$. The desired sequence of amino acids was coupled to the resin using Fmoc-amino acid or Boc-Cys(Npys)-OH or 5(6)-carboxyfluorescein (3.0 equiv), diisopropylcarbodiimide (DIPCDI, 3.3 equiv) and $N$-hydroxy benzotriazole (HOBt, 3.6 equiv), dissolved in DMF. Peptide couplings were monitored using the Kaiser test. After the final Fmoc removal, the resin was subsequently washed with DMF (3 times), dichloromethane (3 times), methanol ( 3 times), dichloromethane (3 times) and diethyl ether ( 3 time) and air-dried for at least $2 \mathrm{~h}$. The peptides were cleaved from the resin by suspension 
in a mixture of TFA/H2O/triisopropylsilane/thioanisole $(90: 5: 2.5: 2.5 \mathrm{v} / \mathrm{v} / \mathrm{v} / \mathrm{v})$ for $2-5 \mathrm{~h}$. The free peptides were precipitated in $\mathrm{Et}_{2} \mathrm{O}$, and the crude products were air dried overnight. The crude peptides were purified by reversedphase HPLC and subsequently lyophilized yielding a yellow powder ( $\mathrm{CbFl}$ labeled peptides) or cream powder (peptides with $\mathrm{N}$-terminal Cys(Npys)). Purity was evaluated by analytical reversed-phase HPLC and identity confirmed by mass spectrometry. All peptides were obtained with a purity greater than or equal to $95 \%$, as assessed by analytical reversed-phase HPLC.

\section{Preparation of extended peptides}

Disulfide linkage between the activating and truncated peptides was achieved by dissolving a fluorescein-labeled short peptide with a free $\mathrm{C}$-terminal cysteine in $0.1 \mathrm{M}$ degassed sodium phosphate buffer ( $\mathrm{pH}$ 7.4) and subsequently mixing it with 1.1 equiv. of the corresponding short peptide with an $\mathrm{N}$ terminal Npys-protected Cys. During this reaction, the final peptide concentration was $1-5 \mathrm{mM}$. The reaction was monitored by reversed-phase HPLC. At the end of the reaction, the resulting peptides were purified by reversed-phase HPLC. After lyophilization, the peptides were obtained as yellow powders. All peptides were obtained with a purity greater than or equal to $95 \%$, as assessed by analytical reversed-phase HPLC. The analytical details are summarized in table S1.

\section{Cell culture}

HeLa cells were maintained in sterile conditions in DMEM supplemented with $10 \%$ heat-inactivated fetal bovine serum. All cells were incubated at $37^{\circ} \mathrm{C}$ in a humidified atmosphere of $7.5 \% \mathrm{CO}_{2}$. Cells were passaged every $2-4$ days.

\section{Flow cytometry}

HeLa cells were seeded in 24-well plates 1 or 2 days prior to the experiment $(40,000$ or 80,000 cells/well). On the day of the experiment, cells were incubated with the peptide solutions ( $5 \mu \mathrm{M}$ or $20 \mu \mathrm{M}$ in medium) for $30 \mathrm{~min}$ at $37{ }^{\circ} \mathrm{C}$. After washing the cells with PBS buffer ( $\mathrm{pH} 7.4$ ), cells were detached by trypsinization for $5 \mathrm{~min}$, spun down and resuspended in $200 \mu \mathrm{L}$ FACS buffer (PBS $+0.1 \mathrm{wt} \% \mathrm{BSA}$ ). The fluorescence was measured using a Beckman Coulter FC500 flow cytometer. Results were based on 10,000 gated cells. Representative histograms are given in Figs. S1-3.

\section{Confocal microscopy}

HeLa cells were seeded in chambered coverslips 1 or 2 days prior to the experiment ( 25,000 or 50,000 cells/well). On the day of the experiment, cells were incubated with the peptide solutions ( $5 \mu \mathrm{M}$ or $20 \mu \mathrm{M}$ in medium) for $30 \mathrm{~min}$ at $37^{\circ} \mathrm{C}$. Cells were washed twice after incubation with medium, and living cells were analyzed immediately by confocal microscopy using a Leica Microsystems SP8 X confocal microscope equipped with an HC PL APO 63x/1.20 W lens. Fluorescein was excited by white light laser at $488 \mathrm{~nm}$ and emission was collected between 500 and $550 \mathrm{~nm}$.

\section{Cytotoxicity assay}

Cytotoxic activity of the CPPs was evaluated for the Hela cells with the WST-8 reagent. Accordingly, Hela cells were seeded at a density of 10,000 cells per well into a 96-well plate and incubated overnight at $37^{\circ} \mathrm{C}$ in $7.5 \% \mathrm{CO}_{2}$ atmosphere. At a confluency of $70 \%$, CPPs were added at final concentrations of 5 and $20 \mu \mathrm{M}$ with three replicates at each concentration. A medium solution without peptide was taken as a background measurement. After $30 \mathrm{~min}$ of incubation at $37{ }^{\circ} \mathrm{C}$ in cell medium, supernatants were discarded and cells were incubated with WST-8 reagent for $4 \mathrm{~h}$. Absorbance was measured at $450 \mathrm{~nm}$ against $650 \mathrm{~nm}$ as a reference wavelength. Results are shown in Fig. S4.

Acknowledgements The Department of General Instrumentation of the Radboud University is thanked for providing light microscopy services.

\section{Compliance with ethical standards}

Conflict of interest The authors declare that they have no conflict of interest.

Informed consent All authors listed have contributed to the conception, design, synthesis, gathering, analysis, or interpretation of data, and have contributed to the writing and intellectual content of the article. All authors gave informed consent to the submission of this manuscript.

Open Access This article is licensed under a Creative Commons Attribution 4.0 International License, which permits use, sharing, adaptation, distribution and reproduction in any medium or format, as long as you give appropriate credit to the original author(s) and the source, provide a link to the Creative Commons licence, and indicate if changes were made. The images or other third party material in this article are included in the article's Creative Commons licence, unless indicated otherwise in a credit line to the material. If material is not included in the article's Creative Commons licence and your intended use is not permitted by statutory regulation or exceeds the permitted use, you will need to obtain permission directly from the copyright holder. To view a copy of this licence, visit http://creativecommons.org/licenses/by/4.0/.

\section{References}

Bode SA, Wallbrecher R, Brock R, van Hest JCM, Löwik DWPM (2014) Activation of cell-penetrating peptides by disulfide bridge 
formation of truncated precursors. Chem Commun 50:415-417. https://doi.org/10.1039/c3cc46826g

Bode SA, Hansen MB, Oerlemans RAJF, van Hest JCM, Löwik DWPM (2015) Enzyme-activatable cell-penetrating peptides through a minimal side chain modification. Biocon Chem 26:850-856. https ://doi.org/10.1021/acs.bioconjchem.5b00066

Bode SA, Kruis I, Adams H, Boelens W, Pruijn G, Van Hest JCM, Löwik DWPM (2017) Coiled-coil mediated activation of oligoarginine cell-penetrating peptides. Chem BioChem 18:185-188. https://doi.org/10.1002/cbic.201600614

Bode SA, Timmermans S, Eising S, van Gemert SPW, Bonger KM, Löwik DWPM (2019) Click to enter: activation of oligo-arginine cell-penetrating peptides by bioorthogonal tetrazine ligations. Chem Sci 10:701-705. https://doi.org/10.1039/c8sc04394a

Brock R (2014) The uptake of arginine-rich cell-penetrating peptides: putting the puzzle together. Biocon Chem 25:863-868. https://doi. org/10.1021/bc500017t

Brooks H, Lebleu B, Vivès E (2005) Tat peptide-mediated cellular delivery: back to basics. Adv Drug Deli Rev 57:559-577. https:// doi.org/10.1016/j.addr.2004.12.001

Chen J, Li S, Shen Q (2012) Folic acid and cell-penetrating peptide conjugated PLGA-PEG bifunctional nanoparticles for vincristine sulfate delivery. Eur J Pharm Sci 47:430-443. https://doi. org/10.1016/j.ejps.2012.07.002

Copolovici DM, Langel K, Eriste E, Langel Ü (2014) Cell-penetrating peptides: design, synthesis, and applications. ACS Nano 8:19721994. https://doi.org/10.1021/nn4057269

Derossi D, Joliot AH, Chassaing G, Prochiantz A (1994) The third helix of the Antennapedia homeodomain translocates through biological membranes. J Biol Chem 269:10441-10450

Feni L, Neundorf I (2017) The current role of cell-penetrating peptides in cancer therapy. In: Sunna A, Care A, Bergquist PL (eds) Peptides and peptide-based biomaterials and their biomedical applications. Springer International Publishing, Cham, pp 279-295

Fischer PM, Zhelev NZ, Wang S, Melville JE, Fahraeus R, Lane DP (2000) Structure-activity relationship of truncated and and substituted analogues of the intracellular delivery vector penetratin. J Pept Res 55:163-172

Hansen MB, van Gaal E, Minten I, Storm G, van Hest JCM, Löwik DWPM (2012) Constrained and UV-activatable cell-penetrating peptides for intracellular delivery of liposomes. J Contr Rel 164:87-94. https://doi.org/10.1016/j.jconrel.2012.10.008

Jiang T, Olson ES, Nguyen QT, Roy M, Jennings PA, Tsien RY (2004) Tumor imaging by means of proteolytic activation of cell-penetrating peptides. PNAS 101:17867-17872. https://doi. org/10.1073/pnas.0408191101

Jiménez-Mancilla N, Ferro-Flores G, Santos-Cuevas C, OcampoGarcía B, Luna-Gutiérrez M, Azorín-Vega E, Isaac-Olivé K, Camacho-López M, Torres-García E (2013) Multifunctional targeted therapy system based on $99 \mathrm{mTc} / 177 \mathrm{Lu}$-labeled gold nanoparticles-Tat(49-57)-Lys3-bombesin internalized in nuclei of prostate cancer cells. J Labelled Comp Radiopharm 56:663-671. https://doi.org/10.1002/jlcr.3087

Jin E, Zhang B, Sun X, Zhou Z, Ma X, Sun Q, Tang J, Shen Y, van Kirk E, Murdoch WJ, Radosz M (2013) Acid-active cell-penetrating peptides for in vivo tumor-targeted drug delivery. J Am Chem Soc 135:933-940. https://doi.org/10.1021/ja311180x

Li N, Li TT, Liu C, Ye SY, Liang JG, Han HY (2016) Folic AcidTargeted and cell penetrating peptide-mediated theranostic nanoplatform for high-efficiency tri-modal imaging-guided synergistic anticancer phototherapy. J Biomed Nanotech 12:878-893. https:// doi.org/10.1166/jbn.2016.2226

Madani F, Lindberg S, Langel Ü, Futaki S, Graslund A (2011) Mechanisms of cellular uptake of cell-penetrating peptides. J Biophys. https://doi.org/10.1155/2011/414729

Morris MC, Gros E, Aldrian-Herrada G, Choob M, Archdeacon J, Heitz F, Divita G (2007) A non-covalent peptide-based carrier for in vivo delivery of DNA mimics. Nucl Acids Res 35:e49-e49. https://doi.org/10.1093/nar/gkm053

Morshed RA, Muroski ME, Dai Q, Wegscheid ML, Auffinger B, Yu D, Han Y, Zhang L, Wu M, Cheng Y, Lesniak MS (2016) CellPenetrating peptide-modified gold nanoparticles for the delivery of doxorubicin to brain metastatic breast cancer. Molec Pharm 13:1843-1854. https://doi.org/10.1021/acs.molpharmaceut.6b000 04

Sharma G, Lakkadwala S, Modgil A, Singh J (2016) The Role of cellpenetrating peptide and transferrin on enhanced delivery of drug to brain. Int J Molec Sci 17:806. https://doi.org/10.3390/ijms1 7060806

Shi N-Q, Qi X-R, Xiang B, Zhang Y (2014) A survey on "Trojan Horse" peptides: opportunities, issues and controlled entry to “Troy". J Contr Rel 194:53-70. https://doi.org/10.1016/j.jconr el.2014.08.014

Wang J, Shen S, Li D, Zhan C, Yuan Y, Yang X (2018) Photoswitchable ultrafast transactivator of transcription (TAT) targeting effect for nanocarrier-based on-demand. Drug Deliv Adv Funct Mat. https://doi.org/10.1002/adfm.201704806

Xie X, Yang Y, Yang Y, Zhang H, Li Y, Mei X (2016) A photo-responsive peptide- and asparagine-glycine-arginine (NGR) peptidemediated liposomal delivery system. Drug Del 23:2445-2456. https://doi.org/10.3109/10717544.2015.1008707

Yamada Y, Hashida M, Harashima H (2015) Hyaluronic acid controls the uptake pathway and intracellular trafficking of an octaarginine-modified gene vector in CD44 positive- and CD44 negativecells. Biomat 52:189-198. https://doi.org/10.1016/j.biomateria 1s.2015.02.027

Yang Y et al (2014) PEGylated liposomes with NGR ligand and heat-activable cell-penetrating peptide-doxorubicin conjugate for tumor-specific therapy. Biomat 35:4368-4381. https://doi. org/10.1016/j.biomaterials.2014.01.076

Zaro JL, Shen W-C (2015) Cationic and amphipathic cell-penetrating peptides (CPPs): their structures and in vivo studies in drug delivery. Front Chem Scie Engin 9:407-427. https://doi.org/10.1007/ s11705-015-1538-y

Publisher's Note Springer Nature remains neutral with regard to jurisdictional claims in published maps and institutional affiliations. 